\title{
Mulheres Surdas e o acesso às informações acerca da Saúde
}

\author{
Thayane Fraga de Paula, Ana Luisa Borba Gediel, Mylene Mayara Santos Dias
}

\begin{abstract}
Resumo
O presente trabalho envolve as temáticas de inclusão e vulnerabilidade social, com o foco nas Mulheres Surdas de classe popular e sua relação com os princípios de igualdade, de respeito à diversidade e de autonomia, inscritos nos princípios da Política Nacional para as Mulheres. Para tanto, realizamos uma pesquisa em uma cidade da Zona da Mata Mineira, durante os anos de 2013 a 2015, com o objetivo de entender como as Mulheres Surdas fluentes em Língua Brasileira de Sinais - LIBRAS, que não estão cadastradas nas Estratégias de Saúde da Família (ESFs), adquirem informações acerca de sua saúde. Para ponderar tais informações, tomamos por base o II Plano Nacional de Políticas para as Mulheres e as diretrizes do Sistema Único de Saúde, no que tange ao exercício dos direitos sexuais e reprodutivos. A partir do desenvolvimento de um estudo etnográfico, utilizando recursos como caderno de campo, etnografia virtual e entrevistas, foi possível adentrar no cotidiano das mulheres Surdas e identificar 6 agentes, com idade entre 25 e 43 anos, usuárias da LIBRAS e que frequentam as unidades de saúde, mas não estão cadastradas nas ESFs. Para o desenvolvimento do estudo obtivemos recursos via FAPEMIG e CNPq. Segundo os dados obtidos pela pesquisa, percebemos a baixa utilização das unidades de saúde para questões relativas à sexualidade e reprodução. Em contra partida, o uso de tecnologias de informação e comunicação foi evidenciado como agency, ou seja, tais mulheres usufruem das Tecnologias de Informação e Comunicação - TICs - para buscar entendimento acerca do próprio corpo e sua sexualidade. Outro aspecto a ser destacado é a autonomia das mulheres surdas em relação às questões que envolvem a surdez e sua cultura, com a ênfase na LIBRAS e na identificação de ser Surda de forma positiva, contrapondo-se à deficiência. Ademais, foram constatadas situações de violência de gênero. $\mathrm{O}$ acompanhamento familiar mostrou-se de modo tutelar (quando as Surdas apresentam pouca agência sobre sua saúde sexual) ou no sentido de interpretação (no caso em que a filha ouvinte faz a tradução para a mãe Surda). A saúde das mulheres Surdas por vezes é prejudicada devido a fatores como barreira linguística, despreparo profissional, tutela e infantilização pelas instituições famílias e, até mesmo, religiosas, o que interfere também no agenciamento que essas mulheres tem sobre seu próprio corpo. A partir desse conjunto de questões averiguadas, entendemos a importância da visibilidade e reconhecimento da necessidade de melhoria das condições de vida e saúde de uma parcela de mulheres, envolvendo a integralidade da saúde e a incorporação de novos segmentos populacionais ao atendimento da Política Nacional de Atenção Integral à Saúde da Mulher.
\end{abstract}

Descritores: Surdas; Direitos Sexuais e Reprodutivos; Saúde da mulher. 